Exploração sexual da criança e do adolescente como trabalho escravo

\title{
EXPLORAÇÃO SEXUAL DA CRIANÇA E DO ADOLESCENTE COMO TRABALHO ESCRAVO*
}

\author{
Eraldo Alves Barboza \\ Universidad de Buenos Aires
}

\section{Resumo}

O tema deste trabalho se refere à exploração sexual de crianças e adolescentes na falsa realidade de trabalho como meio de sobrevivência, principalmente entre a população de menor poder aquisitivo, talvez entre pessoas que vivam abaixo da linha da pobreza.

Para que possamos entender o que se propõe, faremos uma breve explanação acerca do trabalho escravo no Brasil, na qual buscaremos uma ligação com a exploração sexual de crianças e adolescentes, como uma expressão empregada para nomear práticas sexuais por alguns indivíduos inescrupulosos que tiram proveito da situação socioeconômica na ânsia do lucro fácil.

Palavras-chave: prostituição, escravidão, Direitos Humanos, exclusão social.

Autor: Aluno do Doutorado em Direito do Trabalho na Universidade de Buenos Aires (UBA); pósgraduado pela Universidade Cândido Mendes-RJ (2005) e Unigran-MS (2009); graduado em Direito pelo Centro Universitário do Distrito Federal (1992). Advogado e professor das Faculdades Projeção e do Centro Universitário IESB em Brasília-DF.. E-mail: eraldoab@gmail.com

Recibido: 3 de marzo de 2015; evaluado: 10 de abril de 2015; aceptado: 20 de abril de 2015

Trabalho apresentado como requisito de avaliação da disciplina Sociologia Jurídica da Exploração Sexual no Curso de Pós-graduação stricto sensu, Doutorado em Direito do Trabalho pela Faculdade de Direito da Universidade de Buenos Aires (UBA), ministrada pelo Prof. Dr. Misael Tirado Acero.

NOVUM JUS • ISSN: 1692-6013 • Volumen 9 Nº 1 • Enero - Junio 2015 • Págs. 11-28 


\title{
LA EXPLOTACIÓN SEXUAL DE NIÑOS Y ADOLESCENTES COMO TRABAJO ESCLAVO
}

\author{
Eraldo Alves Barboza \\ Universidad de Buenos Aires
}

\section{Resumen}

El tema de este trabajo se refiere a la explotación sexual de niños y adolescentes en la falsa realidad del trabajo como medio de supervivencia, sobre todo entre la población que cuenta con ingresos más bajos, tal vez entre las personas que viven por debajo del umbral de pobreza.

Para entender lo que se propone, haremos una breve explicación sobre el trabajo esclavo en Brasil, en busca de una conexión con la explotación sexual de niños y adolescentes, como una expresión utilizada para denominar las prácticas sexuales por parte de algunos individuos sin escrúpulos que se aprovechan de la situación socioeconómica en el afán de obtener ganancia fácil.

Palabras clave: prostitución, esclavitud, Derechos Humanos, exclusión social.

El autor: abogado en seguridad laboral y social, $\mathrm{PhD}$ in Derecho laboral. Correo electrónico: eraldoab@gmail.com

Recibido: 3 de marzo de 2015; evaluado: 10 de abril de 2015; aceptado: 20 de abril de 2015. 


\title{
THE SEXUAL EXPLOITATION OF CHILDREN AND TEENAGERS AS SLAVE LABOR
}

\author{
Eraldo Alves Barboza \\ Universidad de Buenos Aires
}

\begin{abstract}
This paper presents reports on the sexual exploitation of children and teenagers and the false reality of such work as a means to survive, especially among low-income communities, often below the poverty line.

To understand what is being proposed, we provide a brief explanation of slave labor in Brazil, seeking a connection between the sexual exploitation of children and teenagers. The term is used to define the sexual practices of unscrupulous individuals who take advantage of the social situation and the resulting economic anxiety—mainly poverty and domestic violence — that lead children and teenagers to run away from home and seek refuge in such places in exchange for somewhere to live.
\end{abstract}

Key words: prostitution, slavery, human rights, social exclusion

About the author: labor and social security lawyer,PhD in Labor Law. E-mail: eraldoab@gmail.com

Received: March 3, 2015; reviewed: April 10, 2015; accepted: April 20, 2015.

NOVUM JUS • ISSN: 1692-6013 • Volumen 9 Nº. 1 • Enero - Junio 2015 • Págs. 11-28 


\section{Introdução}

É bem verdade que a prostituição sempre existiu e é extremamente repudiada em toda sociedade. Porém, apesar de ser proibido tirar proveito da prostituição alheia, muitas pessoas insistem nessa prática aliciando pessoas hipossuficientes, em especial crianças e adolescentes, como se fosse meio de sustento delas e de suas famílias.

Apesar do esforço Estatal, a cada ano que passa é possível verificar o aumento desse mercado que tem consumido nossas crianças, nossos jovens e adolescentes, os quais são submetidos às práticas que comprometem o seu desenvolvimento moral, psicológico e ainda intelectual, pois são afastados dos estudos e ficam à mercê da sorte.

Ademais, temos por certo que muitos jovens são traficados e levados a outras localidades com a intenção de serem explorados sexualmente para obtenção de renda. É uma espécie de escravidão moderna, que desenvolve significantemente a indústria do sexo e a distorção dos direitos humanos.

Não raras vezes, podemos observar o turismo sexual à luz do dia nas ruas brasileiras e argentinas, principalmente em locais turísticos, onde essa prática tem crescido consideravelmente.

É com esse propósito que, ao longo deste trabalho bibliográfico, tentaremos demonstrar que a exploração sexual é um trabalho escravo, degradante que agride a formação social, psicológica e moral das crianças e dos adolescentes.

\section{Aspectos históricos da escravidão na sociedade}

O conhecimento moderno de trabalho, segundo Domingos Sávio Zainaghi, ${ }^{1}$ remete aos elementos que originaram a mão de obra humana nas construções das cidades no passado e que foram capazes de compor a história da evolução das sociedades no mundo. Para entender esses elementos, antes de tudo, é preciso analisar o que representa hoje esse crescimento populacional. Todas as obras que temos hoje foram construídas por meio do trabalho humano.

Domingos Sávio Zainaghi, Curso de legislação social - Direito do Trabalho, 12ª ed. Reimpr. (São Paulo: Atlas, 2009), 4.

NOVUM JUS • ISSN: 1692-6013 • Volumen 9 Nº 1 • Enero - Junio 2015 • Págs. 11-28 
É evidente que os anseios das populações que cresciam a cada século demandariam a necessidade da criação de atividades no âmbito laboral para o amparo na vida e sustentação dessa sociedade e do próprio ser humano.

O trabalho então surgiu para colaborar, não só em todas as fases e obras que o homem desenvolveu ao longo de sua história, como também para o desenvolvimento da sociedade capitalista.

Classificada como uma das primeiras formas de trabalho que surgia na antiguidade, a mão de obra escravizada incidia na execução de serviços por pessoas subjugadas por outras. Portanto, o estudo da história da humanidade nos mostra a escravidão como primeira forma de trabalho.

Na visão moderna de Nelson Ramos Barreto, ${ }^{2}$ nas relações de trabalho, tanto na área urbana quanto na rural, existem situações não previstas na legislação trabalhista, mas que não configuram injustiça. Por várias vezes, os trabalhadores preferem não ter assegurados os direitos contidos nos artigos da Consolidação das Leis do Trabalho (CLT) registrados em sua carteira de trabalho profissional, principalmente quando se trata de trabalho temporário. Isso possui constância no campo, pois o trabalho sazonal exige, quase sempre, mão de obra temporária, uma opção que atrai muito mais trabalhadores.

Na história do Brasil, a escravização do homem teve seu início na Colônia, uma formação econômica essencialmente agrícola, e foi extinta, teoricamente, em 1888 com a Lei Áurea. ${ }^{3}$

Para compreendermos o significado de escravidão, devemos nos apegar à expressão usada no Direito, no sentido material, pois o escravo era tido como "res" (coisa, objeto), e não como ser vivente ou pessoa; o seu senhor e dono podia dele dispor como bem desejasse.

Cumpre esclarecer, que a escravidão, seja a presente nas sociedades antigas, seja a colonial, seja a que se verifica em nossos dias, foi sempre um fenômeno de degradação da pessoa humana, de redução do ser humano à condição de mera força de

2 Nelson Ramos Barreto, Trabalho escravo: nova arma contra a propriedade privada (São Paulo: Artpress Indústria Gráfica e Editora, 2004), 10.

3 Maurício Godinho Delgado, Curso de Direito do Trabalho. 10ª ed. (São Paulo: LTr, 2011), 105.

NOVUM JUS • ISSN: 1692-6013 • Volumen 9 Nº 1 • Enero - Junio 2015 • Págs. 11-28 
trabalho, alienada de seus laços familiares, de seu espaço, de sua autonomia, de sua liberdade e de sua dignidade enquanto ser humano. ${ }^{4}$

A relação de trabalho do senhor com o seu escravo era unicamente de usurpação absoluta da liberdade do dono para o seu escravo e o aprisionamento perfazia-se em domínio enclausurado. ${ }^{5}$

Esclarece Arnaldo Sussekind ${ }^{6}$ que o desempenho dos serviços considerados forçosos, pesados, cabia exclusivamente ao escravo, o que levou esse tipo de trabalho ser qualificado, pelos filósofos da antiguidade clássica, como uma função comum e necessária à sobrevivência e à evolução das sociedades no passado. Justificavam tais pensadores que a edificação das cidades e o crescimento de suas economias, além das realizações dos povos da antiguidade no estudo da agricultura e pecuária, somente foram possíveis devido à existência da mão de obra escrava.

Continua afirmando o autor que depois do período da escravidão veio o da servidão, outra forma indireta de obrigar o trabalho excessivo ao homem, que teve seu início no período do feudalismo, no qual os senhores feudais ${ }^{7}$ davam proteção política e militar aos servos que cultivavam as terras em ritmo de perpetuação do labor, pois as obrigações eram transmitidas nas famílias que nunca se viam livres da exploração dos feudos.

Na lição de Domingos Sávio Zainaghr, ${ }^{8}$ esses servos, mesmo não sendo mais escravos, não tinham a liberdade para adquirir novas formas de vida, uma vez que eram dependentes do cultivo da terra para sua sobrevivência. Afirma ainda o autor que o homem já não estava mais sujeito a obedecer a ordens de um senhor, mas era escravo, por assim dizer, de tudo o que produzia e retirava da terra. Em síntese, como já foi verificado e em concordância, Arnaldo Sussekind declara que o escravo era produto de propriedade do seu amo, já o colono era pessoa pertencente a terra. ${ }^{9}$

4 Ricardo Rezende Figueira, Adonia Antunes Prado, Horácio Antunes de Sant’Ana Júnior, organizadores. Trabalho escravo contemporâneo: um debate transdisciplinar. Rio de Janeiro: Mauad X, 2011, 179. Arnaldo Sussekind, Curso de direito do trabalho. $3^{a}$ ed., ver. e atual. (Rio de Janeiro: Renovar, 2010), 4. Arnaldo Sussekind, Curso de direito do trabalho, 4

Senhores feudais eram pessoas que possuíam muito poder político, militar e econômico. Eram proprietários dos feudos (unidades territoriais) e possuíam muitos servos que trabalhavam para eles.

8 Sávio Zainaghr, Curso de legislação social - Direito do Trabalho. 12ª ed. Reimpr. (São Paulo, Atlas, 2009), 6.

9 Arnaldo Sussekind, Curso de direito do trabalho, 6.

NOVUM JUS • ISSN: 1692-6013 • Volumen 9 Nº. 1 • Enero - Junio 2015 • Págs. 11-28 
Após a Revolução Industrial, emerge nas sociedades a contratação de proletários livres, mas com novas formas de trabalho. Dessa alteração profunda das relações sociais e econômicas no meio urbano e nas condições de vida dos trabalhadores, desenvolveu-se o regime do contrato de trabalho assalariado, em que suas características eram formuladas ainda exclusivamente pelas imposições do empregador, principalmente no que se referia às condições salariais.

Dessa trajetória da coletividade pós-industrial para os grandes aglomerados urbanos, com o intenso deslocamento das pessoas da área rural para as cidades, acabaramse gerando enormes concentrações populacionais e, consequentemente, a procura desesperada dessas pessoas por trabalho. Salienta-se que o trabalho era exercido nas grandes fábricas com um agrupamento de operários num mesmo local, o que levou, então, a uma conscientização entre eles a respeito das condições precárias em que trabalhavam e a um sentimento de revolta, formado contra a exploração que lhes era imposta. ${ }^{10}$

Contra a opressão dos assalariados por empresários cada vez mais ávidos na elevação de suas economias, tomados pelo desejo ao abuso do esforço de seres humanos, a legislação social-trabalhista não só surgia com o objetivo de limitação à autonomia da vontade nessas relações injustas de trabalho, mas também designava dentro dos parâmetros laborais sistemas obrigatórios de previdência social para resguardar o futuro daqueles trabalhadores. ${ }^{11}$

Ainda no final do século XIX, em 1891, a Igreja Católica mostrou sua preocupação com as relações escravagistas existentes no mundo. Isso ocorreu por meio do pronunciamento do então pontífice, Papa Leão VIII, o qual externou sua opinião sobre a exploração inadmissível dos trabalhadores pobres, que se emana o surgimento de leis trabalhistas. ${ }^{12}$

Com o aumento das funções e responsabilidades do Estado, cresce, conjuntamente, a seriedade do Poder Executivo, que passa, desde então, a editar maior número de atos normativos que vêm regulamentar a sua atuação. Nessas condições, o âmbito do Direito Privado, mais necessariamente pelo Direito Civil, é invadido pelo Direito

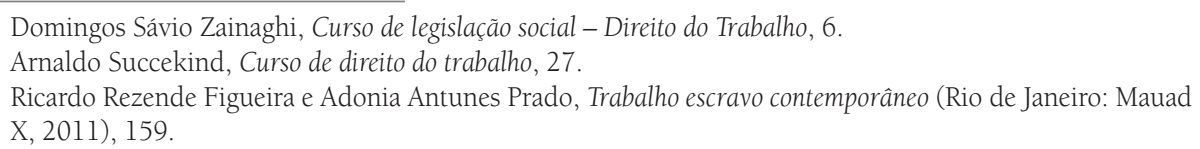

NOVUM JUS • ISSN: 1692-6013 • Volumen 9 №. 1 • Enero - Junio 2015 • Págs. 11-28 
Público, que passa a intervir na autonomia da vontade desse direito coibindo os abusos até então verificados e ainda não superados. ${ }^{13}$

O intervencionismo estatal transpõe seus interesses mostrando acentuada interpretação das normas nas relações individuais de trabalho. Para Amauri Mascaro do Nascimento, ${ }^{14}$ ao utilizar em seu raciocínio as palavras de autores como Lazcano, Amiaud, Barassi, entre outros, o autor afirma que o direito do trabalho, historicamente, provém do direito civil e do contrato de locação de serviços previstos naquele diploma legal. Devido a isso, o intervencionismo estatal não desfigura essa característica de o direito do trabalho ser diretamente ramo do direito privado, porque é uma qualidade própria da história e evolução desse direito. Sua significância vai da época em que foi imposto na sociedade, igualmente aos demais ramos do direito, como o direito de família, de sucessões, o direito comercial etc.

Verificada a parte da evolução histórica nas relações de trabalho no desenvolvimento do modo de aquisição de mão de obra na produção capitalista, constatou-se que essa primeira modalidade de trabalho, a escravidão, causou vários efeitos na evolução do sistema capitalista no qual se desenvolveu toda a antiguidade clássica greco-romana.

O escravo pertencia ao senhor dono do poder, e sua disciplina jurídica estava, portanto, nos direitos reais, ou seja, nos direitos de propriedade da coisa ou produto. Com a forma de trabalho já caracterizada como servidão, constatou-se que o dever de fidelidade do servo era restrito para com a gleba e havia uma notória vinculação da sua vida e de seus familiares ao imóvel, terreno da produção do seu trabalho.

É possível traçar um paralelo entre a escravidão trabalhista e a escravidão sexual. No passado, conforme dito linha atrás, a escravidão surgiu como uma das primeiras formas de trabalho, isto é, execução de serviços por pessoas subjugadas, com a finalidade de construir civilizações.

Após milhares de anos, verificamos que a prática escravista ainda continua, porém fantasiada de outras formas, como, por exemplo, a exploração sexual. Crianças, jovens e adultos são obrigados a venderem seus corpos, subjugados à prática de todo tipo de lascívia em benefício de outras pessoas.

13 Francisco Rossal de Araújo, A boa fé no contrato de emprego (São Paulo: LTr, 1996), 57.

14 Amauri Mascaro Nascimento, Curso de Direito do Trabalho: história e teoria geral do direito do trabalho: relações individuais e coletivas do trabalho. $26^{a}$ ed. (São Paulo: Saraiva, 2011), 355. 
$\mathrm{Na}$ historicidade, o abuso sexual sempre esteve presente, porém no passado tinha teor ritualístico, em meio a práticas consagradas por sociedades, que não o considerava abuso devido à vitimização da pessoa, ou seja, a prática sexual não era vista como um dano, as pessoas não se consideravam vítimas de abuso sexual.

\section{O valor do trabalho como Direito Humano}

Para Américo Piá Rodriguez, ${ }^{15}$ a sociedade, na medida em que contribui para aumentar o lucro e melhorar o clima social das relações entre as partes, além de dar segurança ao trabalhador, constitui não apenas um benefício para esse trabalhador, enquanto lhe transmite uma sensação de tranquilidade econômica, mas também recai em benefício para o próprio empregador, pois ambos, empregado e empregador, visam à conservação da fonte de trabalho.

Sabemos que o trabalho dignifica o homem em razão de sua inserção social quando participa dos meios de produção e leva-o também ao consumo. Contudo, em pleno século XXI, ainda há pessoas que pensam que a prostituição é uma forma de trabalho que pode dignificar o ser humano.

Em maio de 2009, uma decisão do Superior Tribunal de Justiça (STJ) causou perplexidade e consternação em todo o território nacional quando disse que a exploração sexual de adolescentes submetidos à prostituição não importaria na prática do crime tipificado no artigo 244-A, da Lei 8.069/1990, qual seja: "Submeter criança ou adolescente, como tais definidos no caput do art. $2^{\circ}$ da referida Lei, à prostituição ou à exploração sexual".

Tenho a impressão que o Egrégio Tribunal em nenhum momento se lembrou de que a Constituição Federal, em seu artigo 227, diz que "é dever da família, da sociedade e do Estado assegurar à criança, ao adolescente e ao jovem, com absoluta prioridade, o direito à vida, à saúde, à alimentação, à educação, ao lazer, à profissionalização, à cultura, à dignidade, ao respeito, à liberdade e à convivência familiar e comunitária, além de colocá-los a salvo de toda forma de negligência, discriminação, exploração, violência, crueldade e opressão". ${ }^{16}$ Isso inclui também colocá-lo a salvo da exploração sexual.

15 Américo Plá Rodríguez, Princípios de Direito do Trabalho. 3a . Ed. Atual. (São Paulo: LTr, 2000), 240.

16 Brasil, Constituição da República Federativa do Brasil (Brasília, DF: Senado Federal: Centro Gráfico, 1988), art. 227.

NOVUM JUS • ISSN: 1692-6013 • Volumen 9 Nº 1 • Enero - Junio 2015 • Págs. 11-28 
Nenhum trabalho que tenha como finalidade a exploração sexual de crianças e adolescentes pode ser classificado como direito humano. É bom lembrar que o Estatuto da Criança e do Adolescente (ECA), por sua vez, além de reafirmar, em seu artigo $4^{\circ}$, que dentre os direitos fundamentais a serem assegurados a todas as crianças e adolescentes pela família, comunidade, sociedade em geral e Poder Público, encontram-se os direitos ao respeito eà dignidade; em seu artigo 17 ainda dispõe que "direito ao respeito consiste na inviolabilidade da integridade física, psíquica e moral da criança e do adolescente" e, de forma textual, o artigo 18, do mesmo Diploma Legal, assevera ser "dever de todos velar pela dignidade da criança e do adolescente, pondo-os a salvo de qualquer tratamento desumano, violento, aterrorizante, vexatório ou constrangedor". ${ }^{17}$

Todo ser humano, enquanto membro de uma sociedade, tem direito ao trabalho, isso é inegável. Entretanto, não podemos jamais classificar como trabalho digno a exploração sexual, não só de jovens, mas de toda e qualquer pessoa.

\section{A exploração sexual}

Cumpre esclarecer que as aulas expositivas do prof. Dr. Misael Tirado foram extremamente importantes para o entendimento de que a exploração sexual comercial deve ser analisada e compreendida dentro da sistemática capitalista e da sociedade consumidora globalizada, isto é, um contexto no qual muitas pessoas pensam que se trata de atividade econômica necessária para o desenvolvimento do país.

Para que possamos entender melhor o significado de exploração, buscamos seu significado no dicionário Aurélio: "ato ou efeito de explorar"; [...] 2. tentativa de tirar proveito ou utilidade de alguma coisa (a boa ou má parte); [...] 3. o que se explora; 4. abuso da boa-fé, da situação precária, da ignorância (de alguém, para auferir interesses); 5 . especulação vergonhosa. ${ }^{18}$

Exploração sexual comercial de crianças e adolescentes é uma relação de mercantilização e abuso do corpo de crianças por exploradores sexuais, organizados

17 Amauri Mascaro Nascimento diz que "especial proteção é dispensada pelo direito do trabalho ao menor por meio de um conjunto de disposições que tem por objetivo assegurar a educação, o desenvolvimento físico, a saúde e a sua moralidade". (Direito contemporâneo do trabalho, 417).

18 Gilberto Dimenstein, Meninas da noite: a prostituição de meninas-escravas no Brasil. 13a ed. (São Paulo: Ática, 1997), 123. 
em redes de comercialização local ou global, ou por pais ou responsáveis e por consumidores de serviços sexuais pagos. ${ }^{19}$

A exploração sexual e econômica de crianças e adolescente vai muito além de conceitos previamente elaborados. Ela se funde dentro do abuso, da violação dos direitos de um ser.

Já mencionamos alhures que no Brasil a exploração sexual de uma criança nem sempre é vista como um abuso sexual. Dentre tantas violações que o crime de tráfico engloba, esta é uma delas.

É importante ressaltar que a violência sexual contra crianças e adolescentes é uma violação dos direitos da pessoa humana e da pessoa em desenvolvimento, direitos à integridade física e psicológica, ao respeito e à dignidade, ao desenvolvimento físico, psicológico, moral e sexual sadios. No mercado do sexo, são violados seus direitos à convivência familiar e comunitárias protetoras e ao trabalho não explorado, digno, seguro, adequado à idade, não degradante, direitos estes garantidos no ECA. ${ }^{20}$

Durante muito tempo, pouco se falava acerca da exploração sexual, na qual crianças e adolescentes eram participantes ativos desse comércio, identificadas como prostitutas mirins. Com a globalização, a criação do chamado turismo sexual, a chegada avassaladora da internet como meio de divulgação da pornografia infantil, um novo significado foi dado a tudo isso.

A partir da década de 1990, as autoridades brasileiras perceberam que a exploração sexual era um crime do qual todos eram vítimas, pois grandes organizações criminosas transformavam nossas crianças e adolescentes em mercadorias sexuais.

Não restam dúvidas de que hoje a exploração sexual engloba outras práticas além da prostituição obrigatória, tais como a pornografia infantil, a pedofilia, o turismo sexual e o próprio tráfico de pessoas.

19 Maria Lucia Leal e Maria de Fátima Pinto Leal (orgs.), Pesquisa sobre tráfico de mulheres, crianças e adolescentes para fins de exploração sexual no Brasil. Relatório Final (Brasília: CECRIA, 2003).

20 Vicente de Paula Faleiros, "A violência sexual contra crianças e adolescentes e a construção de indicadores: a crítica do poder, da desigualdade e do imaginário", em Indicadores de violência familiar e exploração sexual comercial de crianças e adolescentes, organizado por Maria de Fátima Pinto Leal e Maria Auxiliadora Cesar (Brasília: CECRIA, 1998), 46

NOVUM JUS • ISSN: 1692-6013 • Volumen 9 Nº 1 • Enero - Junio 2015 • Págs. 11-28 
Em 1996, em Estocolmo, na Noruega, ocorreu o I Congresso Mundial contra a Exploração Sexual e Comercial de Crianças e Adolescente. Nessa ocasião, ficaram evidentes as diversas práticas criminosas que atingem crianças e adolescentes em todo o mundo, quais sejam:

- turismo sexual;

- pornografia;

- prostituição;

- tráfico para fins sexuais. ${ }^{21}$

Neste trabalho bibliográfico, tentaremos mostrar que a exploração sexual é semelhante ao trabalho escravo, degradante, que reduz a dignidade da pessoa humana a nada.

O que mais nos causa indignação é saber que, para as crianças e adolescentes que são explorados, existe uma grande demanda, geralmente composta por pessoas adultas e instruídas, conhecedoras e conscientes de que estão cometendo crime.

\section{A exploração sexual da criança e do adolescente como trabalho escravo}

Não há ainda, no nosso ordenamento jurídico, a figura do cliente como fato típico, ou seja, como crime. No entanto, a partir do III Congresso Mundial contra a Exploração Sexual de Crianças e Adolescente, houve ratificação de uma lei que prevê a punição dos delitos que são praticados por meio da internet, pelo então presidente Luiz Inácio Lula da Silva.

A Ex-Senadora de República Patrícia Sabóia, que presidiu uma Comissão Parlamentar de Inquérito (CPI) que investigou a exploração sexual de crianças e adolescentes entre os anos de 2003 e 2004, apresentou um projeto de lei que criava a figura típica do cliente, no caso de exploração sexual de crianças e adolescentes.

Sabemos que a legislação internacional é bastante clara no que se refere aos Direitos Humanos da criança e do adolescente. Dentro desses aspectos protetivos, sem dúvida nenhuma, está a proteção contra qualquer tipo de tratamento degradante, qualquer tipo de abuso ou exploração sexual.

21 Congresso de Estocolmo, Relatório do Congresso Mundial contra a Exploração Sexual Comercial de Crianças (Suécia: Unicef, ECPAT e Grupo de ONGs para a Convenção dos Direitos da Crianças, 1996). 
Dentre os direitos que protegem a criança e o adolescente, está a garantia de um meio ambiente sadio para que possam evoluir, crescer e se tornarem cidadãos. Apesar de parecer, não estamos diante de uma anomia, ou seja, falta de leis. Muito ao contrário, temos vários dispositivos legais que punem a exploração sexual de crianças e adolescentes.

Ademais, a Convenção 182 da Organização Internacional do Trabalho (OIT), ratificada pelo Brasil, em seu artigo $3^{\circ}$, diz que a expressão das piores formas de trabalho infantil compreende: "todas as formas de escravidão ou práticas análogas à escravidão, como venda e tráfico de crianças, sujeição por dívida, servidão, trabalho forçado ou compulsório, inclusive recrutamento forçado ou compulsório de crianças para serem utilizadas em conflitos armados; utilização, demanda e oferta de criança para fins de prostituição, produção de material pornográfico ou espetáculos pornográficos etc." ${ }^{22}$

A prostituição é o ato de dispor do próprio corpo para práticas sexuais com a finalidade comercial. Esse termo não é utilizado, pelo menos não é recomendado, para crianças e adolescentes porque a prostituição pressupõe um ato de vontade. É uma expressão da liberdade sexual de o indivíduo poder dispor ou não do seu próprio corpo. ${ }^{23}$

No entanto, para crianças e adolescentes, a doutrina e a jurisprudência utilizam a expressão exploração sexual já que a sua vontade não está imune a vícios de consentimento. A legislação civil, ao considerar a criança e o adolescente absolutamente incapaz e relativamente incapaz, respectivamente, não lhes dá capacidade para dispor do seu próprio corpo.

Destarte, quando há "exploração sexual", estamos diante de uma relação de trabalho com o uso sexual, para fins sexuais, mediante pagamento. A exploração sexual tem a mesma relação com o trabalho escravo, degradante.

Nos locais mais longínquos do Brasil, a prática do trabalho escravo e degradante é uma realidade, principalmente onde existem carvoarias. As pessoas são submetidas a jornadas desumanas e chegam a trabalhar mais de 16 horas por dia em condições desumanas.

Gilberto Dimenstein, Meninas da noite: a prostituição de meninas-escravas no Brasil, 156.

Guilherme Assis de Almeida, Direitos humanos e não-violência (São Paulo: Atlas, 2001), 54

NOVUM JUS • ISSN: 1692-6013 • Volumen 9 Nº 1 • Enero - Junio 2015 • Págs. 11-28 
Quando falamos que a exploração sexual de crianças e adolescentes é trabalho escravo, deve-se a que muitas pessoas na sociedade consideram que tais práticas são necessárias como meio de vida, ou seja, exploração sexual-comercial de crianças e adolescentes é trabalho. Eles acreditam que as crianças e adolescentes estão buscando naquela atividade a sua sobrevivência e de suas famílias. ${ }^{24}$

É importante esclarecer que essa prática ocorre com maior frequência nas camadas mais pobres da população, em que crianças e adolescentes se veem explorados sexualmente não apenas pela pobreza, mas também porque estão vivenciando ou vivenciaram situações de violência dentro de casa, o que leva a que elas abandonem seu lar e se submetam à exploração sexual, até pela própria família. ${ }^{25}$

Não restam dúvidas que a exploração sexual, pelo menos nessa situação, caracteriza trabalho, pois estão presentes alguns elementos do contrato de trabalho, quais sejam: habitualidade, pessoalidade e onerosidade. Na realidade, evidenciamos o quanto essas crianças e adolescentes são vítimas dessa situação e como se faz necessário que a sociedade a enfrente já que estamos diante de todos os elementos integrantes do trabalho forçado na exploração sexual-comercial.

Aliás, a própria OIT, em toda a sua estrutura normativa e doutrinária que ela patrocina, não deixa de se referir à exploração sexual infantil como uma das formas de trabalho forçado.

Não podemos nos esquecer da pornografia infantil, a qual de uma forma ou de outra mantém uma relação estreita com a exploração sexual para fins comerciais. Lembrando que pornografia é toda e qualquer exposição de crianças e adolescentes em situações libidinosas. Havendo a finalidade de explorar comercialmente tal exposição, é exploração sexual. ${ }^{26}$

Não restam dúvidas de que a exploração sexual é trabalho escravo, forçado. Isso acontece quando homens e mulheres são obrigados a trabalhar sexualmente, sob coação não necessariamente física, para que permaneçam nas atividades sexuais.

24 Alberto Silva Franco, "Submissão de criança ou adolescente à prostituição ou à exploração sexual", Boletim IBCCrim, ano 9, 109/3-5 (dez. 2001): 22.

25 Polícia Federal, Relatório sobre o Tráfico de Mulheres, Crianças e Adolescentes para fins de Exploração Sexual, (Brasília: MJ/DPF/DPCI/Interpol, 2001).

26 Lineu Escorel Borges, Repressão no Brasil ao tráfico internacional de crianças = repression du trafic international d'enfants au bresil: relatório = rapport (Recife: Lexml, 1992). 
Podemos mencionar como exemplo o que acontece frequentemente com mulheres que são levadas a outros países com a promessa de emprego e, quando chegam lá, seus passaportes são subtraídos e são forçadas a trabalhar como prostitutas. ${ }^{27}$

Com crianças e adolescentes, o trabalho forçado se presume, isso devido ao vício de vontade. Elas não têm capacidade para aceitar e para praticar atos dessa natureza. O trabalho sexual livre é aquele feito por adultos, sem situação de exploração nem de coação. Existe desde que o mundo é mundo. Aliás, algumas pessoas advogam que a prostituição para adultos, desde que realizada como ato livre, deveria ser regulamentada, porque, na realidade, ela é até sugerida pelo Ministério do Trabalho e Emprego. ${ }^{28}$

Na realidade, a opção sexual é arbítrio de cada ser humano, então, nesse aspecto, cabe ao Estado decidir se sai da hipocrisia regulamentando a atividade sexual como atividade laboral. Nesse caso, diminuirá a exploração sexual, porque o fenômeno social será tratado como ele realmente é. Não adianta pensar que, no Brasil, não há prostituição, quando ele é o maior exportador de prostitutas para o mundo inteiro, de todas as ordens: homens, mulheres e travestis. ${ }^{29}$

Cabe salientar que, durante a exposição das aulas pelo prof. Dr. Misael Tirado, foi possível notar que o trabalho sexual pode, inclusive, revestir-se de todas as formas de trabalho que se entende no Direito do Trabalho brasileiro, a saber: o trabalho subordinado e habitual, previsto na CLT e que, na verdade, não é lícito; o trabalho eventual, quando eventualmente alguém precisa de dinheiro e se prostitui; o trabalho autônomo, quando a prostituta não está vinculada a nenhuma entidade que a explore. É preciso que se diga: este é um trabalho que jamais pode ser exercido por crianças e adolescentes, porque destrói a possibilidade da criança e do adolescente crescer com dignidade e se tornar um cidadão.

\section{Conclusão}

Finalmente, é possível, sob o aspecto sociológico, traçar um paralelo entre a escravidão trabalhista e a escravidão sexual. No passado, conforme dito linhas atrás, a

Gilberto Dimenstein, Meninas da noite: a prostituição de meninas-escravas no Brasil, 157

Alberto Silva Franco, "Submissão de criança ou adolescente à prostituição ou à exploração sexual", 23.

Comissão Europeia. Justiça e Assuntos Internos, Tráfico de mulheres. A miséria por trás da fantasia: da pobreza à escravatura sexual. Uma estratégia global (2001). http://europa.eu/rapid/press-release_MEMO-01-64_pt.htm (acesso em 7 jul. 2015).

NOVUM JUS • ISSN: 1692-6013 • Volumen 9 Nº 1 • Enero - Junio 2015 • Págs. 11-28 
escravidão surgiu como uma das primeiras formas de trabalho, ou seja, execução de serviços por pessoas subjugadas, com a finalidade de construir civilizações.

Após milhares de anos, verificamos que a prática escravista ainda continua, mas travestida de outras formas, como, por exemplo, a exploração sexual. Crianças, jovens e adultos são obrigados a venderem seus corpos, subjugados à prática de todo tipo de lascívia em benefício de outras pessoas.

Na historicidade, o abuso sexual sempre esteve presente, porém no passado tinha teor ritualístico, em meio a práticas consagradas por sociedades, pois naquela época não se considerava abuso, ou seja, não implicava um dano à pessoa.

É fundamental mudar os paradigmas valorativos, éticos, jurídicos e de enfrentamento; portanto, são as políticas sociais o meio e não o fim, e devem ter como eixo central os direitos humanos e uma política de proteção integral à criança e ao adolescente, que considere assim particularidades regionais, culturais, sociais e políticas.

É preciso a implantação e o fortalecimento dos Conselhos de Direitos e Tutelares para monitoramento, controle e fiscalização da violação dos direitos, com um fortalecimento das redes de informações sobre a violação dos direitos da pessoa e, em especial, a punição de todo e qualquer tipo de exploração sexual contra crianças e adolescentes.

Dessa forma, para que o tema seja concluído, com base na defesa dos Direitos Humanos e dos Direitos e Garantias Fundamentais, como a dignidade da pessoa humana, a liberdade, o direito à privacidade, o direito à intimidade e à segurança pessoal de cada um, faz-se necessário ao Estado se organizar cada vez mais, no sentido de fortalecer a sua intervenção social, por meio da relação que existe entre ele e a sociedade civil. Além disso, é impossível não destacar que a precarização do trabalho é central para a questão social, porque leva as pessoas para diferentes meios de submissão à exploração de seus corpos e de seus trabalhos.

É importante esclarecer que a sociedade de todo o mundo encontra-se numa situação extremamente problemática, complexa e que a proteção deve ser buscada a todo custo; ainda, precisa-se ter uma visão clara do contexto daquela criança, daquele adolescente, da questão da sua família, em que situação ela está, se ela está numa situação de rua ou não, se ela mora na rua ou não. Só assim poderemos, por meio de políticas públicas, consolidar a verdadeira proteção à criança e ao adolescente. 


\section{Bibliografia}

Almeida, Guilherme Assis de. Direitos humanos e não-violência. São Paulo: Atlas, 2001.

Araújo, Francisco Rossal de. A boa fé no contrato de emprego. São Paulo: LTr, 1996.

Barreto, Nelson Ramos. Trabalho escravo: nova arma contra a propriedade privada. São Paulo: Artpress Indústria Gráfica e Editora, 2004.

Borges, Lineu Escorel. Repressão no Brasil ao tráfico internacional de crianças = repression du trafic international d'enfants au bresil: relatório = rapport. Recife: Lexml, 1992.

Brasil, Constituição da República Federativa do Brasil. Brasília, DF: Senado Federal: Centro Gráfico, 1988.

Comissão Europeia. Justiça e assuntos internos. Tráfico de mulheres. A miséria por trás da fantasia: da pobreza à escravatura sexual. Uma estratégia global. 2001. http://europa. eu/rapid/press-release_MEMO-01-64_pt.htm (acesso em 7 jul. 2015).

Congresso de Estocolmo. Relatório do Congresso Mundial contra a Exploração Sexual Comercial de Crianças. Suécia: Unicef, ECPAT e Grupo de ONGs para a Convenção dos Direitos da Crianças, 1996.

Delgado, Maurício Godinho. Curso de Direito do Trabalho. 10ª ed. São Paulo: LTr, 2011.

Dimenstein, Gilberto. Meninas da noite: a prostituição de meninas-escravas no Brasil. $13^{a}$ ed. São Paulo: Ática, 1997.

Faleiros, Vicente de Paula. "A violência sexual contra crianças e adolescentes e a construção de indicadores: a crítica do poder, da desigualdade e do imaginário" em Indicadores de violência familiar e exploração sexual comercial de crianças e adolescentes, organizado por Maria de Fátima Pinto Leal e Maria Auxiliadora Cesar, 37-54. Brasília: CECRIA, 1998.

Figueira, Ricardo Rezende e Adonia Antunes Prado. Trabalho escravo contemporâneo. Rio de Janeiro: Mauad X, 2011.

Franco, Alberto Silva. "Submissão de criança ou adolescente à prostituição ou à exploração sexual". Boletim IBCCrim, ano 9, 109/3-5 (dez. 2001): 45-78.

Guimarães, Marilu. Comissão parlamentar de inquérito destinada a apurar a responsabilidade pela exploração e prostituição infanto-juvenil. Brasília: Câmara dos Deputados. Coordenação de Publicações, 1998.

Leal, Maria de Fátima Pinto (org.). Pesquisa sobre tráfico de mulheres, crianças e adolescentes para fins de exploração sexual comercial. Relatório Nacional, Brasil. Brasília: CECRIA, 2002.

Leal, Maria Lucia e Maria de Fátima Pinto Leal (orgs.). Pesquisa sobre tráfico de mulheres, crianças e adolescentes para fins de exploração sexual no Brasil. Relatório Final. Brasília. CECRIA, 2003.

Ministério da Justiça. Plano Nacional de Enfrentamento da Violência Sexual InfantoJuvenil. Brasília: Ministério da Justiça, Secretaria de Estado de Direitos Humanos e

NOVUM JUS • ISSN: 1692-6013 • Volumen 9 Nº 1 • Enero - Junio 2015 • Págs. 11-28 
Departamento da Criança e do Adolescente, 2001. http://www.sdh.gov.br/assuntos/ bibliotecavirtual/criancas-e-adolescentes/publicacoes-2013/pdfs/plano-nacionalde-enfrentamento-da-violencia-sexual-contra-crianca-e-adolescentes (acesso em 7 jul. 2015).

Miranda, Adriana Andrade, Carolina Tokarski, Lívia Gimenes, Márcia Vasconcelos, Raissa Rousseng e Talitha Selvati. OIT. Cidadania, direitos humanos e tráfico de pessoas - Manual para promotoras legais populares, 2009. http://www.justica.sp.gov.br/StaticFiles/SJDC/ ArquivosComuns/ProgramasProjetos/NETP/cidadania_direitos_humanos_372. pdf (acesso em 7 jul. 2015).

Nascimento, Amauri Mascaro. Curso de Direito do Trabalho: história e teoria geral do direito do trabalho: relações individuais e coletivas do trabalho. 26ª ed. São Paulo: Saraiva, 2011.

O tráfico de crianças brasileiras: um horror restrito aos leitores de Brasília: Dossiê. Brasília, DF: Inesc, 1994.

Polícia Federal. Relatório sobre o Tráfico de Mulheres, Crianças e Adolescentes para fins de Exploração Sexual. Brasília: MJ/DPF/DPCI/Interpol, 2001.

Plá Rodriguez, Américo. Princípios de Direito do Trabalho. $3^{a}$ ed. Atual. São Paulo: LTr, 2000.

Ricardo Rezende Figueira, Adonia Antunes Prado, Horácio Antunes de Sant'Ana Júnior, organizadores. Trabalho escravo contemporâneo: um debate transdisciplinar. Rio de Janeiro: Mauad X, 2011.

Unicef. Matriz de Enfrentamento à Exploração Sexual Comercial de Crianças e Adolescentes. Brasília: Unicef, 2005.

Sussekind, Arnaldo. Curso de direito do trabalho. $3^{\text {a }}$ ed., ver. e atual., Rio de Janeiro: Renovar, 2010.

Zainaghi, Domingos Sávio. Curso de legislação social - Direito do Trabalho. 12ª ed. Reimpr. São Paulo: Atlas, 2009. 